\title{
MICRO RESISTÊNCIAS E MACRO POTÊNCIAS EM ESPAÇOS URBANOS: PERSPECTIVAS PARA O DESIGN
}

MICRO RESISTANCES AND MACRO POWERS IN URBAN SPACES: PERSPECTIVES FOR DESIGN

BRUNA MONTUORI, M.SC. | ROYAL COLLEGE OF ART, SCHOOL OF ARCHITECTURE - UK

MARIA CECILIA LOSCHIAVO DOS SANTOS, Dra. | FAU-SP

MARIA LUIZA DIAS VIANA, M.SC.|FAU-USP

\begin{abstract}
RESUMO
Este trabalho tem como objetivo levantar reflexões sobre ações coletivas organizadas e realizadas em duas favelas, com foco no uso e na transformação de espaços urbanos. Com base em reflexões teóricas do design e do urbanismo e no relato de duas diferentes experiências de intervenção popular em espaços públicos, pretende-se discutir como ações coletivas podem levantar e trazer questões para esses campos. Propõe-se investigar questões críticas do campo do design no que tange ao seu envolvimento em ações de interesse comunitário que buscam ressignificar espaços e modos de vida nas cidades.
\end{abstract}

PALAVRAS CHAVE: Design; participação; colaboração; cocriação; conceitos; urbanidade.

\begin{abstract}
This paper aims to reflect upon collective actions organized and carried out in two Brazilian favelas focusing on the use and transformation of urban spaces. Based on theoretical reflections of design and urban studies and on the report of two different experiences of artistic intervention in public spaces, we discuss how collective actions can rais eawareness and bring questions to these areas of study. The article proposes an investigation on critical issues in the field of design regarding its involvement in collective and participatory actions of community interest seeking to redefine spaces and ways of life in cities.
\end{abstract}

KEY WORDS: Design, participation, collaboration, co-creation, concepts, urbanity. 


\section{INTRODUÇÃO}

Nossas cidades e suas estruturas utilitárias, tal como define o arquiteto Marcos Rosa (2015), foram planejadas e construídas a partir de visões tecnocráticas de urbanismo. Desde o início do século $X X$, as grandes metrópoles se espelharam em modelos urbanísticos internacionais que priorizavam o uso do automóvel, a industrialização e a construção de infraestruturas de larga escala. Já em meados de 1950, a ideologia modernizadora proveniente das estratégias de desenvolvimento internacionais assinalava sua prioridade no progresso e no avanço técnico científico a todo custo (ESCOBAR, 1995, p. 3-4).

Nas últimas décadas, especialmente após os anos 1990, saltamos de uma ideologia baseada no progresso racionalista para outra baseada no discurso do capital digital. Trata-se da era das cidades globais e inteligentes baseadas no conceito de Smart Cities, suportadas pelo interesse do capital privado sobre o espaço urbano, conforme Poli de Figueiredo (2018), que continuam a perpetuar as desigualdades, a exclusão geográfica, a segregação e a apagar as culturas e as identidades locais, sobretudo das populações pobres, como afirma Escobar (1995). No Brasil, como em muitas cidades de países do Sul Global, de acordo com Arantes et al (2002), trata-se de uma acirrada crise urbana, de disputas iminentes de capitalização, em que a especulação imobiliária, a industrialização, a gentrificação, entre outros fatores, afeta e define a qualidade dos espaços da cidade.

Deste modo, compreendemos a ação coletiva cidadã nos usos e na transformação dos espaços públicos como aspecto fundamental para revisarmos o lugar de fala do design e seu papel nas cidades. Reconhecemos estes espaços como coletivos, em que os encontros ocorrem a partir de interesses comuns, permitindo a participação de múltiplos atores, Rosa (2015). Trata-se da conexão entre arte, urbanidade e política que transforma os usos dos espaços, e consequentemente, as relações entre cidades e cidadãos.

Neste sentido, ambicionamos discutir em que medida essas ações podem levantar aprendizados e elucidar outras formas de ação para o design. Trata-se de ampliar seu repertório e suas relações, partindo do reconhecimento de que os ditos "usuários", são, na verdade, atores sociais com múltiplas perspectivas, demandas e habilidades, que estão além da noção de consumidores passivos. Para isso, vale refletirmos na relação entre design, uso e usuário a partir da abordagem de Johan Redström (2012);

Ao passo que o design e a pesquisa em design certamente atravessaram um longo caminho desde os primeiros dias do desenho industrial para produção em massa e consumo em massa, nós ainda lutamos com a articulação de relações entre projetar e usar que se diferencia significativamente de um entendimento que primeiro designers projetam, depois usuários usam. (REDSTRÖM in GUNN; DONOVAN, 2012, p. 83)

Com o intuito de romper com tais concepções, este trabalho foi estruturado em três eixos norteadores: (1) localizar o lugar de fala do design na atual conjuntura social e política; (2) posicionar as práticas cidadãs de ação coletiva no espaço público diante da presente cultura de design e levantar o papel de tais práticas criativas e sua habilidade de ressignificação espacial, a partir de dois casos, um no contexto de Belo Horizonte, no Morro do Papagaio, e outro no Rio de Janeiro, no Complexo da Maré; (3) Apresentar reflexões sobre como tais experiências podem se relacionar com o design, principalmente no campo do design participativo.

Para tanto, pretende-se discutir algumas abordagens e conceitos do design frente a essas ações, com o intuito de apontar perspectivas no que tange o apoio às práticas espaciais que ocorrem no contexto dessas comunidades.

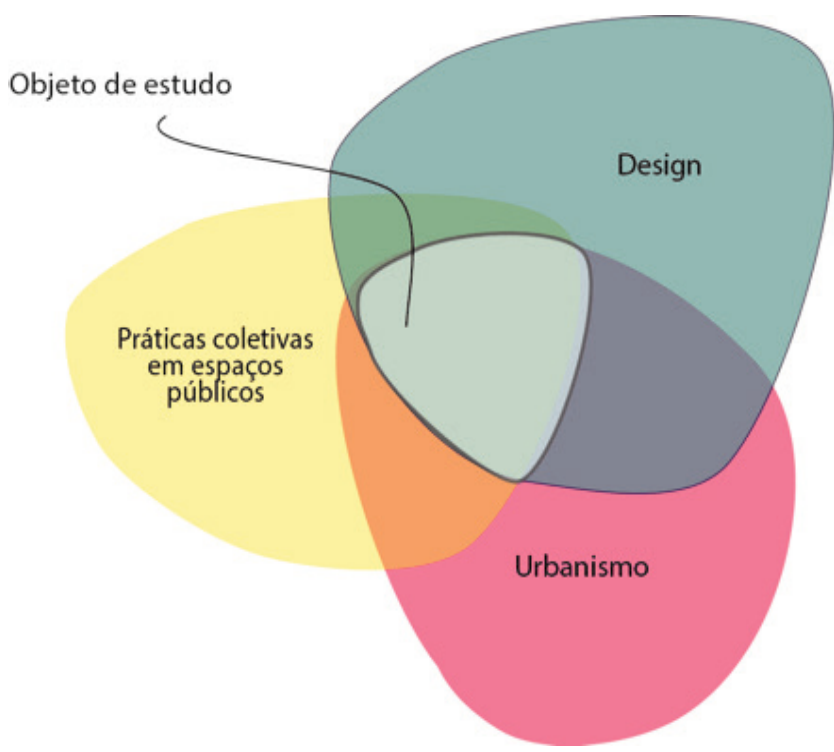

Figura 01 - Abrangência Fonte: Autoras.

\section{PERSPECTIVAS CONCEITUAIS}

Em um presente contexto de crise em que o Norte Global luta por justiça climática e questões latentes de imigração, o Sul Global ainda lida com conflitos sociais urbanos e rurais, compartilhamento de espaço público, ocupação e exploração de terras e falta de autonomia social, como aborda Escobar (2016). Com o intuito de se aproximar destas questões, jovens designers estão cada vez mais envolvidos em práticas de design colaborativas, mais 
conscientes dos resultados de se realizar coletivamente, ao invés de considerar seus usuários meros objetos passivos de estudo. Sanders e Stappers (2008).

Como aponta Escobar, "o design está inextricavelmente ligado às decisões sobre o tipo de vida que vivemos e os mundos onde vivemos. " (ESCOBAR, 2016, p. 50-52 tradução das autoras). $O$ autor afirma que estamos em um momento em que as atividades projetuais estão se abrindo para os campos das ciências humanas, tais como a geografia e a antropologia, de modo que profissionais vêm aplicando novos métodos que enfatizam a investigação nas fases iniciais do processo, intercambiando seu papel entre facilitador e mediador, ao invés de especialista;

...concebendo o design como eminentemente centrado no usuário, participativo, colaborativo e radicalmente contextual; eles tentam tornar inteligíveis e conhecedores os processos e estruturas que nos cercam, para induzir aos usuários uma alfabetização ecológica e de sistemas; etc. Acima de tudo, (...), há uma tentativa de construir visões culturais alternativas como motores da transformação social através do design." (ESCOBAR, 2016, p. 50-52 - tradução da autora).

Nas décadas de 1960 e 1970, o designer Aloisio Magalhães abordou sobre a responsabilidade social no design ao questionar: "o que o desenho industrial pode fazer pelo país?" (MAGALHÃES, 1998, p. 8-12). Ele acreditava que estes mesmos problemas seriam resolvidos por meio da cultura popular articulada a prática projetual e a ampla produtividade industrial Magalhães in (LEITE, 2014). Para Escobar, "muitas vezes o objetivo dos designers era meIhorar os bens produzidos em massa e a qualidade de vida das pessoas através do uso de novos materiais e técnicas. " (ESCOBAR, 2016, p. 52). No entanto, o cenário enfrentado hoje, de modo geral, distanciou-se ao que Magalhães havia pensado para os designers brasileiros, isto é, uma prática projetual industrial democrática e atenta às questões sociais e culturais nacionais. Além do design no país não ser considerado um meio para viabilizar soluções democráticas, especialmente para estratos sociais pouco favorecidos. É compreensível que alguns profissionais saem a campo para trabalhar com não designers e seus problemas da vida cotidiana, porém há poucas experiências que atendam as inúmeras demandas deste público.

Ao passo que designers lidam cada vez mais com problemas sociais e comportamentos interpessoais, acredita-se necessária uma melhor compreensão sobre o modo como operam os diferentes sistemas sociais. Antes de engajarem-se em demandas puramente propositivas, é necessário reconhecerem as diferenças de poder e hierarquias existentes, nas trocas e posicionarem frente à essa perspectiva, como projetistas. Em outras palavras, trata-se de reconhecer e identificar o locus social de fala e de poder dos profissionais de projeto (RIBEIRO 2017; ALCOFF 2008), para então assumir que há um obstáculo epistemológico entre a produção de conhecimento do campo em relação ao conhecimento produzido por inteligências locais. Neste sentido, acredita-se que compreender as diferenças epistemológicas exige um exercício de alteridade. A alteridade envolve o reconhecimento do outro, de maneira que os diálogos sejam horizontais e as diferenças e conflitos sejam igualmente legitimados, ainda que as forças de poder sejam díspares. O designer Gui Bonsiepe sugere que alteridade é a "palavra que significa colocar-se no lugar do outro na relação interpessoal, com respeito e consideração, valorização etc." (BONSIEPE, 2011, p. 38). Para Paola B. Jacques (2019) trata-se de "incorporar o outro em nós mesmos como uma rejeição as estruturas hegemônicas". (JACQUES, 2019 - Vídeo). No entanto, realizar ações pautadas na alteridade em processos de colaboração é ainda um desafio, especialmente porque profissionais de áreas propositivas, como designers e arquitetos, são ainda reconhecidos como especialistas, figuras centrais em processos de inovação. Em contrapartida, aqueles que conhecem e fazem parte da construção social e física dos espaços, detêm uma inteligência sobre eles que vai além do conhecimento técnico, funcional e de sua forma. Trata-se de um conhecimento empírico que carrega narrativas, memórias e relações sociais que, muitas vezes, são invisíveis aos olhos dos profissionais. Em razão disso, trabalhar com alteridade implica em promover integração não apenas com outras disciplinas, mas com saberes locais, a partir de diálogos plurais com citadinos, permitindo que o debate e o conflito sejam democráticos.

Reforçando esta ideia, Maria Cecilia Loschiavo dos Santos (2003) sugere que além do conceito de design pautado no culto dos produtos e em sua literatura histórica;

... há outro sentido em questão (...) que corresponde às práticas realizadas em bases espontâneas, por pessoas desprovidas, visando sua sobrevivência. Não se trata mais da celebração do star design, mas sim da celebração da habilidade humana de fazer design, mesmo sob condições extremamente difíceis." (SANTOS, 2003, p.23)

Entende-se a partir deste raciocínio que é preciso uma atenção especial para a leitura de situações de complexidade urbana, tal como coloca a pesquisadora Lucrécia Ferrara (2002) ao se referir diretamente ao âmbito do projeto, como algo pouco desenvolvido na formação de profissionais; 
O projeto mostra ao desenho sua dimensão social interessada e interesseira que lhe permite superar os condicionantes da tecnologia dos materiais e seus procedimentos. Esta dimensão social, mais uma vez, transforma competência do saber fazer no desempenho de saber por que se faz, com a atenção flexível daqueles que estão à espreita, observando os caminhos inventivos disponíveis; nessa tarefa o projeto é claramente atenção, observação e comparação entre projetos e usos. (FERRARA, 2002, p. 52)

A necessidade de afastamento das práticas racionalistas no design é evidenciada a partir da constante mudança no papel de profissionais, especialmente por meio de práticas contínuas de colaboração, o que requer uma revisão crítica sobre os impactos gerados em ações sociais e participativas no design. Por conta disso, reconhecemos que não se trata de desenvolver apenas processos de design, envolvendo colaboração e mudança de comportamentos. Trata-se de evitar a inserção de interpretações afirmadas pelo status quo como o melhor caminho para alcançar desenvolvimento e potencializar as ações que já estão envolvidas com preocupações reais, questões existentes já aprofundadas ou emergentes, ainda em formulação ou não formuladas. Escobar (2016). Todavia, é possível compreender o modo como o modelo econômico capitalista sempre afetou a nossa consolidação cultural, principalmente a popular, de modo que fôssemos treinados a nos espelhar prioritariamente nos estilos de vida europeu e estadunidense. Segundo Nestor Canclini (1989) as culturas subalternas são impedidas de um desenvolvimento independente ou alternativo, pois reorganizam sua estrutura social e linguagem de acordo com a produção e o consumo, para se adaptarem ao desenvolvimento capitalista. Ele ainda afirma em relação as "culturas subalternas populares ", como resultado de uma apropriação desigual do capital cultural, uma elaboração própria de suas condições de vida e uma interação em conflito com os setores hegemônicos." (CANCLINI, 1989, p.39). O mesmo vale para a construção da formação pedagógica brasileira em design, que foi apoiada em referências alemãs de ensino em design. José Luiz Mendes Ripper (MONTUORI in BRAGA; FERREIRA, 2017, 79-99) conta que até o horário as aulas ESDI - Escola Superior de Design Industrial, em suas primeiras décadas de ensino, bem como suas atividades de laboratório eram idênticas às da Bauhaus, ao passo que nem o clima tropical brasileiro era levado em consideração na formulação acadêmica. É interessante notar, conforme relata Aloísio Magalhães à posteriori, que "a carência de originalidade deu lugar à exuberante presença da cópia e o gosto mimético por outros valores culturais". (MAGALHÃES, 1998, p. 11)

Com base nestas constatações e diante de um contexto de disparidades sociais, surgem as seguintes questões: Qual o papel social dos designers brasileiros nesta atual interface sócio-econômica-política? Como estes (as) podem agir e contribuir para uma atuação nas cidades, como profissionais e cidadã (aos)? Ou como Fezer (2010,) coloca;

Ao fazer referência à 'cidade', tanto como processo e como o cotidiano - como uma dimensão concreta da realidade - o propósito de projeto será refletido novamente: como seria o design se fosse inspirado por uma abordagem aberta, processual, micropolítica, intervencionista, comunicativa e participativa que se relaciona com a vida urbana cotidiana? Seria destinado a ser apenas um elemento na colonização mercantilizada dos espaços sociais, ou poderia ser uma ferramenta estratégica com um caráter político e social que pode contribuir essencialmente para uma cidade social? (FEZER, 2010)

O design, com reconhecimento já consolidado nos campos da ciência e das tecnologias, tem papéis que vão além de sua função de projetar produtos, visto que se trata de uma ciência social aplicada. Este ponto de vista, aqui adotado, quer evidenciar que o projeto de design deve levar em consideração as vivências, demandas, necessidades e desejos das pessoas, não somente como usuárias de produtos e serviços, mas como cidadãos e praticantes espaciais, valorizando sua história e a cultura local.

Apontamos o papel e a responsabilidade social desta profissão no que diz respeito à proposição participativa e inclusiva, especialmente em contextos de vulnerabilidade sociais, como o do Morro do Papagaio em Belo Horizonte e do Complexo da Maré, no Rio de Janeiro. Estes carregam uma trajetória complexa de disputa e de resistência em que a habilidade de transformar e questionar o uso do espaço se dá a partir de uma resiliência coletiva constante dos indivíduos.

Com o intuito de reforçar a relevância do coletivo em detrimento aos interesses individuais, Magalhães aborda a posição do artista contemporâneo diante de mudanças sociais na década de 1960 , uma reflexão que pode estendida para o design. Ele afirma que a posição do artista em nosso tempo teria que ser revista: “... no momento, o que interessa é a larga informação, o coletivo. Não tem mais sentido no nosso mundo o artista fazer objeto único, o quadro desligado do contexto social no qual ele vive". (MAGALHÃES in LEITE, 2014, p. 36-37). Por uma 
perspectiva semelhante, o arquiteto e pesquisador Rahul Mehrotra (1998) questiona a distância destes profissionais de seu papel em sistemas complexos urbanos, durante seus estudos e projetos em Mumbai:

Arquitetos e designers que trabalham nestes contextos urbanos agora estão lidando com uma gama inteira de problemas e questões sociais, culturais e econômicos que muitas vezes são estranhos às suas profissões. Na práxis convencional, o arquiteto profissional não se envolve neste conjunto mais amplo de questões, mas opta por operar com a especificidade de um local, no processo, muitas vezes se desconectando do contexto de prática maior. O crescimento urbano sem precedentes é um desafio para os profissionais de design para redefinir seu papel na sociedade. (MEHROTRA, 1998, p. 7 - tradução das autoras)

Para ambos os autores, sejam artistas, designers ou arquitetos, há uma urgência de participação e inserção no contexto social e político, de forma que suas atividades evitem práticas isoladas e descontextualizadas. Lidamos com uma realidade na qual designers enfrentam a necessidade de integração por outros caminhos, limitados para profissionais de campos criativos e majoritariamente importados de outros países. Assim, vale-se da ideia de que o campo do design é estruturalmente pautado em atividades sociais, já que está inserido socialmente, seja na sua forma institucionalizada ou popular como afirma Fernanda Cardoso (2010). Assim, valorizamos um design voltado para práticas sociais e democráticas, expandidas para além do projeto técnico industrial mercadológico e próximas das realidades sociais do país e das práticas populares. Este viés representa uma reorientação do foco tradicional e cultural do campo, que migra do seio das atividades econômicas neoliberais Guy Julier (2013) para uma atitude que estimula junto aos usuários "mudanças que venham de dentro" e possam "ensaiar novos cenários" (LENSKJOLD et al, 2015, 71 - tradução da autora).

Na cultura popular da favela, vale-se da inventividade e da criatividade local, a fim de solucionar problemas e emancipar inteligências locais. Deste modo, esta construção apoia-se em uma atividade plural e situacional que visa aprender com ações coletivas espontâneas e de participação já existentes. Estas reflexões teóricas nos auxiliam a compreender o lugar de fala do design, principalmente no que se refere a adoção de um fazer projetual que se permite e se deixa levar pelas circunstâncias, desafios e potencialidades do contexto que se trabalha. A seguir apresentamos nosso entendimento sobre experiências criativas nas cidades e suas relações com a presente cultura de design, detalhando dois casos selecionados e realizamos a partir deles, as reflexões que estas nos oferecem para iluminar a prática do design.

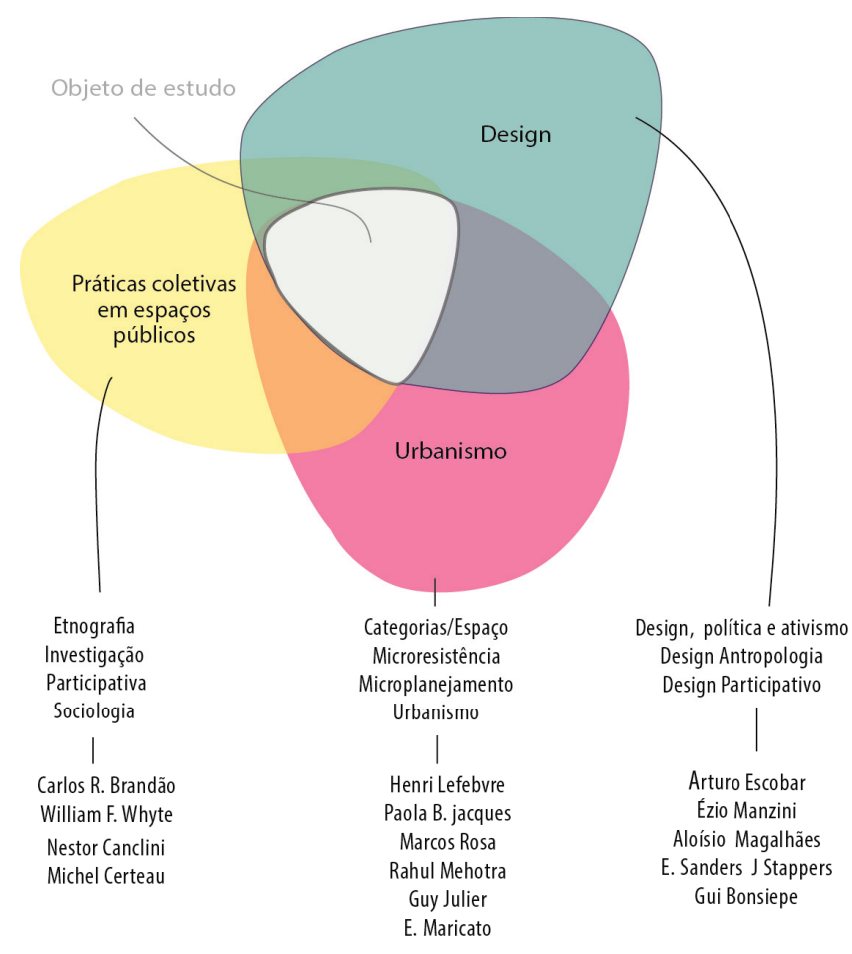

Figura 02 - Síntese do referencial teórico e conceitual Fonte: Autoras.

\section{PRÁTICAS URBANAS CRIATIVAS: MICRO RESISTÊNCIA E MACRO POTÊNCIA}

Este artigo parte do pressuposto de que a qualidade que determina os espaços públicos das cidades está muito mais associada aos modos como eles são utilizados e partilhados pelos indivíduos e grupos, do que por aquilo que é determinado no seu estatuto de propriedade ou pelo seu planejamento. Ou seja, entende-se que o valor dos espaços públicos diz respeito mais às experiências de uso que as pessoas fazem dos locais onde vivem, circulam ou convivem e àquilo que elas são capazes de criar e produzir neles e a partir deles. Neste sentido, apresenta a perspectiva de pensar espaços públicos das cidades como espaços coproduzidos, entendendo a cidade como local para ações, intervenções e transformações produzidas por seus habitantes. De fato, podemos perceber explicitamente nas cidades, uma lógica predominante atrelada aos modos de produção e da economia, porém, devemos compreender a existência de outra perspectiva nas cidades, a de se reconstruir continuamente, a partir de ações cotidianas dos cidadãos, voltadas para os interesses comuns, para a qualidade de vida. Observa-se neste 
sentido, um contrapondo entre uma universalidade de valores técnicos, planejados e as particularidades das práticas sociais muitas vezes espontâneas que ocorrem em contextos espaços temporais flexíveis.

Michel de Certeau (2014) sugere estas ações como táticas, que subvertem as estratégias providas pelas ordens de poder superiores, institucionais. Enquanto as estratégias definem o espaço da cidade tal qual ele é, e suas grandes estruturas e equipamentos, as táticas vem para subverte-las, criando brechas de ação que são próprias e não determinadas, acontecendo em instantes. Há em algumas zonas geográficas da cidade, em vários aspectos negligenciadas pela sociedade e pelas políticas públicas, ações artísticas críticas que atualizam e renovam os modos de participação das pessoas na vida pública.

Próximas do campo artístico, tais intervenções atualizam a cidade enquanto um modo de construção ativa de sentidos. Nos abrindo para outros modos de envolvimento, outros poros de percepção, nos permitindo penetrar no terreno do sensível, ultrapassar significados instituídos, já vistos e previstos nas cidades. Para nós, referem-se a formas de micro resistência ou desvios da lógica espetacular das cidades. A lógica espetacular, como afirma Paola B. Jacques (in ROSA, 2011) ao se referir ao pensamento consensual, único que transforma o espaço público em cenário, "espaços desencarnados, fachadas sem corpos, espaços pacificados" Jacques (in ROSA, 2011, p. 166). Como contraponto a essa lógica espetacular que homogeiniza as sensibilidades, a autora aponta para um tipo de urbanismo mais incorporado, não consensual, de dissenso, que vai além da visualidade imagética hegemônica.

Para muitos que passam e vivem nestes locais, estas atividades geram qualidades e "propriedades" para o espaço urbano, de modo diferencial, pois resultam também de interações, entre atores sociais, coletivos que operam, projetam e modelam de modo não contínuo as extensões do espaço. Pensando nessas relações e contradições entre as diferentes funcionalidades dos espaços urbanos, remetemos também ao filósofo Henri Lefebvre (1999) que distingue para isso duas categorias; o espaço homogêneo e o espaço diferencial. Ao espaço homogêneo, ele atribui a ideia do espaço planificado, "sem topia" sem lugares, sem contrastes, como da indiferença pura. E ao espaço diferencial, ele remete as diferenças que emergem, se instauram e se instalam no espaço, reunido, confrontado pela/na realidade urbana. São contrastes, oposições, sobreposições, que surgem em substituição aos distanciamentos, às distâncias espaço temporais. Lefebvre faz referência aos sentidos dos lugares (topias), que procedem imediatamente da natureza: das particularidades do solo, da fauna, da flora. No entanto, quando a heterogeneidade da natureza é substituída pela racionalidade quantitativa do espaço industrial, há a predominância do espaço homogêneo. Neste caso, trata-se quase sempre, da ideia do espaço representado somente em função de critérios produtivistas. $O$ diferencial é quando o espaço urbano difere radicalmente desta continuidade precisamente homogênea. O que inclui a integração de grupos marginalizados, produzindo interferências nas realidades.

Dentro deste campo, selecionamos e apresentamos aqui duas experiências que ocorrem em territórios distintos e com algumas similaridades e que incidem nos territórios específicos de duas favelas brasileiras, o Complexo da Maré no Rio de Janeiro e o Morro do Papagaio em Belo Horizonte, que foram pesquisados pelas autoras.

A ideia é de entrecruzar o caráter participativo inerente a essas práticas existentes e o sentido de ressignificação que elas promovem, e apontar aspectos relacionados ao design. Trata-se de reconhecer as favelas como lugares de uma riqueza cultural própria, de potência e de resistência. Para isso é importante considerar que a noção de favela no senso comum está relacionada à ausência de infraestrutura, de serviços ou simplesmente à ideia de um território de exclusão e de violência e que até os anos 1980 elas sequer apareciam nos mapas das cidades e eram vistas como espaços externos à polis. O que se propõe aqui é compreender a potência das Favelas a partir de algumas ações coletivas que ocorrem em condições específicas, capazes de propor ressignificações nesses territórios.

Uma das ações é o projeto Favela Bela, uma iniciativa de moradores do Morro do Papagaio em Belo Horizonte que propõe intervenções urbanas nos espaços públicos locais. São pinturas produzidas em muros, fachadas, escadarias, becos e outros suportes urbanos, organizadas e realizadas pelos próprios moradores com a colaboração de artistas, apoiadores e comerciantes locais.

O Morro do Papagaio, localiza-se na Região Centro Sul de Belo Horizonte, numa área de aproximadamente 477.000 m2. Constitui-se pelas comunidades; Vila Santa Rita, Vila Estrela, Bicão, Predinhos, e Barragem Santa Lúcia.

Conforme o IQUV' índice de Qualidade de Vida Urbana da Prefeitura de Belo Horizonte, o aglomerado possui um índice do 0,553 , considerando que o maior na cidade é 0,869 e o menor 0,464. De acordo com dados do IBGE - Instituto Brasileiro de Geografia e Estatística, sua população é de cerca de 17mil pessoas. O Morro do Papagaio é uma das áreas mais vulneráveis de Belo Horizonte, de acordo com a ONU - Organização das Nações Unidas, seu IDH ${ }^{2}$ - o Índice de Desenvolvimento Humano, é de 0,685 , um dos mais baixos da cidade, podendo ser comparado ao índice dos países mais pobres do mundo. 


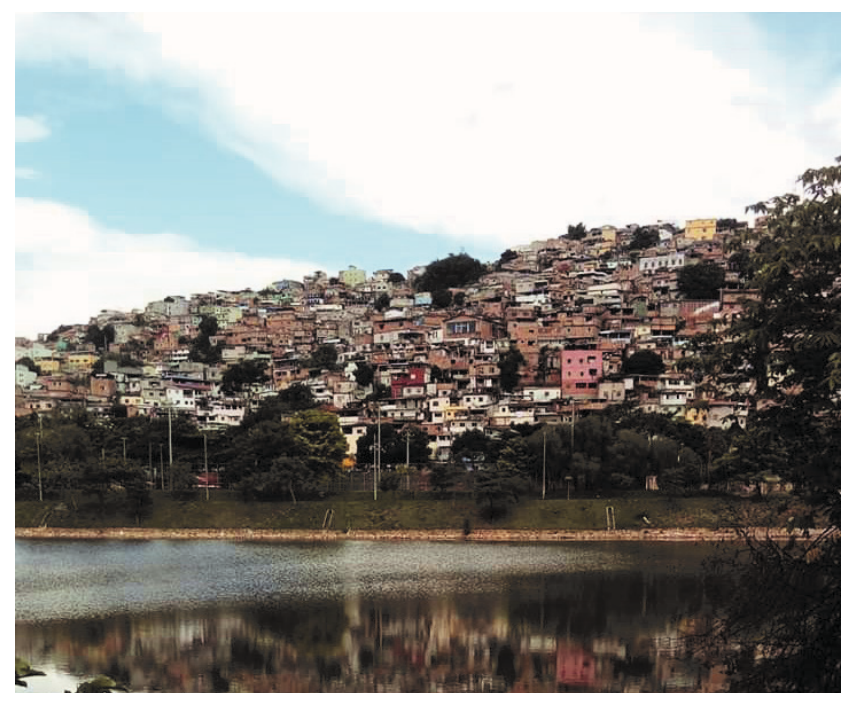

Figura 01 - Barragem Santa Lúcia, ao fundo o Morro do Papagaio - Belo Horizonte. Foto: Maikon Sipriano, 2019

Fonte: Maikon Sipriano, 2019

O projeto Favela Bela envolve a transformação dos espaços da favela, envolvendo todos agentes em ações de interesse público, promovendo a experiência estética numa perspectiva coletiva, lúdica, educativa e participativa. A escolha dos locais, escadarias e becos, se dá estrategicamente pelo fato destas, serem estruturas importantes dentro da lógica de circulação no Morro que possibilitam a integração de um lado com outro e funcionam como lugares não somente de passagem, mas como referência. Para os organizadores as pinturas destes locais são feitas para chamar a atenção das pessoas para o cuidado, a limpeza, a memória local ou pelo uso indevido pelo tráfico de drogas e outras ações ilícitas. A organização é feita pelas mídias sociais e pela articulação no local.

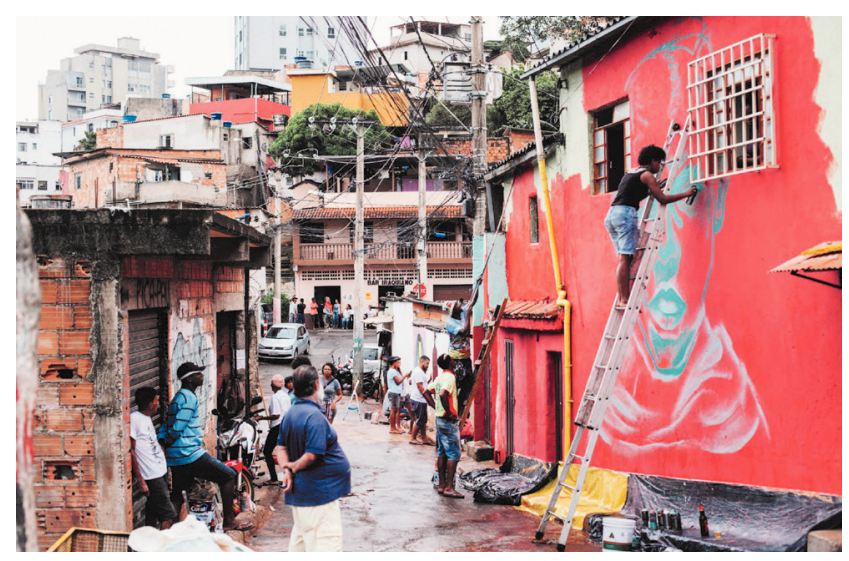

Figura 02 - Pintura nas fachadas da Vila Estrela - Morro do Papagaio. Fonte: Maria Luiza Viana, 2018.

As fachadas e muros são pintados a partir de uma negociação entre os moradores e os artistas, sobre a cor ou algum tema. Nos dias das pinturas, esses espaços se transformam em lugares de compartilhamento, de troca entre os moradores, entre aqueles que circulam e visitantes, pessoas de outros locais da cidade que vão ao Morro para participar do evento. Os materiais são doados por comerciantes locais e externos e o lanche é fornecido de forma compartilhada por todos os participantes.

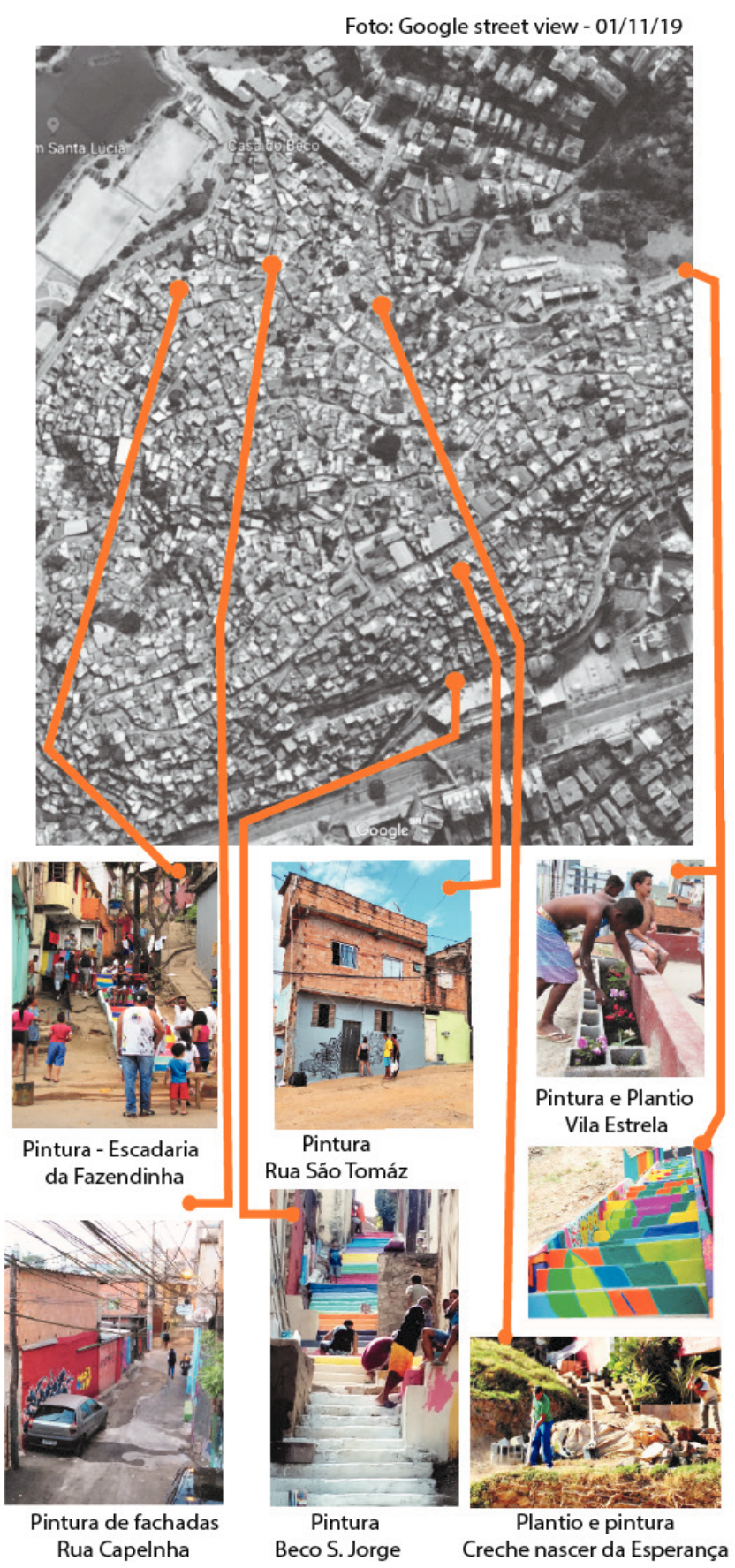

Figura 03 -Algumas ações do Projeto Favela Bela -Morro do Papagaio - BH realizadas em 2018 e 2019. A Barragem Santa Lúcia está situada na parte superior e esquerda da foto. Fonte: Maria Luiza Viana

Durante o evento acontecem as pinturas, e também atividades de jardinagem e outras, como apresentações musicais de samba e de DJs e de estamparia (silk) de camisetas, com 
imagens criadas para o próprio evento e impressas no local.

Para o Projeto Favela Bela, o mais importante é a mobilização dos moradores e a conscientização de que qualquer transformação na comunidade depende do envolvimento e da participação de todos.

No caso do conjunto de favelas da Maré, no Rio de Janeiro, tratamos do projeto Maré Sem Fronteiras, realizado entre 2013 e 2017 e desenvolvido pela organização de interesse público Redes de Desenvolvimento da Maré, Montuori (2018). O conjunto de favelas da Maré (Figura 4) possui 16 comunidades e teve seu início na década de 1940 nas margens da Baía de Guanabara, Zona Norte do Rio de Janeiro (Figura 5). Ao longo das décadas, desde as primeiras favelas auto-construídas -Morro do Timbau (1942), Baixa do Sapateiro (1947), Conjunto Marcílio Dias (1948) e Parque Maré (1953)diversos programas de urbanização e habitação social foram desenvolvidos. $O$ resultado é um complexo território, dividido em comunidades constantemente ameaçadas de remoção e afetadas por repressões policiais, especialmente durante o período ditatorial Jacques (in Varella et al. 2002).

De acordo com o Censo Populacional da Maré, desenvolvido pela Redes da Maré (2019), o território possui aproximadamente 140 mil moradores, totalizando $47 \mathrm{mil}$ moradias. $O$ território é localizado entre duas grandes vias expressas - a Avenida Brasil e a Via expressa João Goulart (Linha Vermelha) - e é cortada por uma terceira, a Avenida Governador Carlos Lacerda (Linha Amarela) que conecta a Zona Norte à Zona Oeste. Ao lado do território se encontra a llha do Fundão, onde está localizado o aeroporto internacional Antonio Carlos Jobim e a Universidade Federal do Rio de Janeiro (UFRJ).

Em 1994, o território foi oficialmente reconhecido como um bairro da cidade apesar de suas precárias infraestruturas, dando finalmente a alguns de seus residentes o direito ao título de propriedade (BRUM, 2019). Ainda hoje, a Maré sofre privações de acesso a transporte público e sofre com graves problemas de densidade populacional, falta de infraestrutura urbana, questões com lixo e limpeza urbana, além da insuficiência de serviços públicos. Ao mesmo tempo, sua histórica carrega uma longa trajetória de movimentos sociais lutando por seus direitos fundamentais - evidente nas primeiras associações de moradores e em atuais organizações e instituições originadas localmente. Sua linha do tempo sugere que a autonomia e a habilidade de lidar com a falta de responsabilização do Estado foram passadas entre gerações e estão presentes em seus habitantes.

Atualmente, o território é segregado em três partes (Figura 6) comandadas por três grupos armados - atuantes no tráfico de drogas e armas-, em que um deles é a milícia.
Ao mesmo tempo, a Polícia Militar do Rio de Janeiro realiza operações policiais provocando confronto armado entre os grupos locais, provocando inúmeras mortes, principalmente de jovens negros ${ }^{3}$. Tal aspecto perpetua a relação de fronteiras no território em que moradores lidam com questões de estereótipos entre as comunidades da Maré, bem como afeta a circulação de pessoas pelo território (Sousa Silva, 2015).

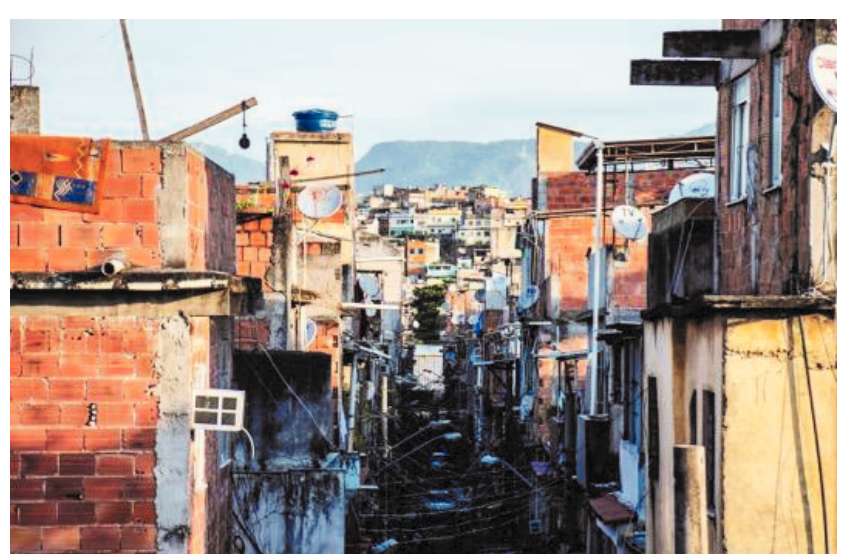

Figura 04 - Nova Holanda (1962) com vista para Morro do Timbau (1942). Foto: Douglas Lopes, 2017

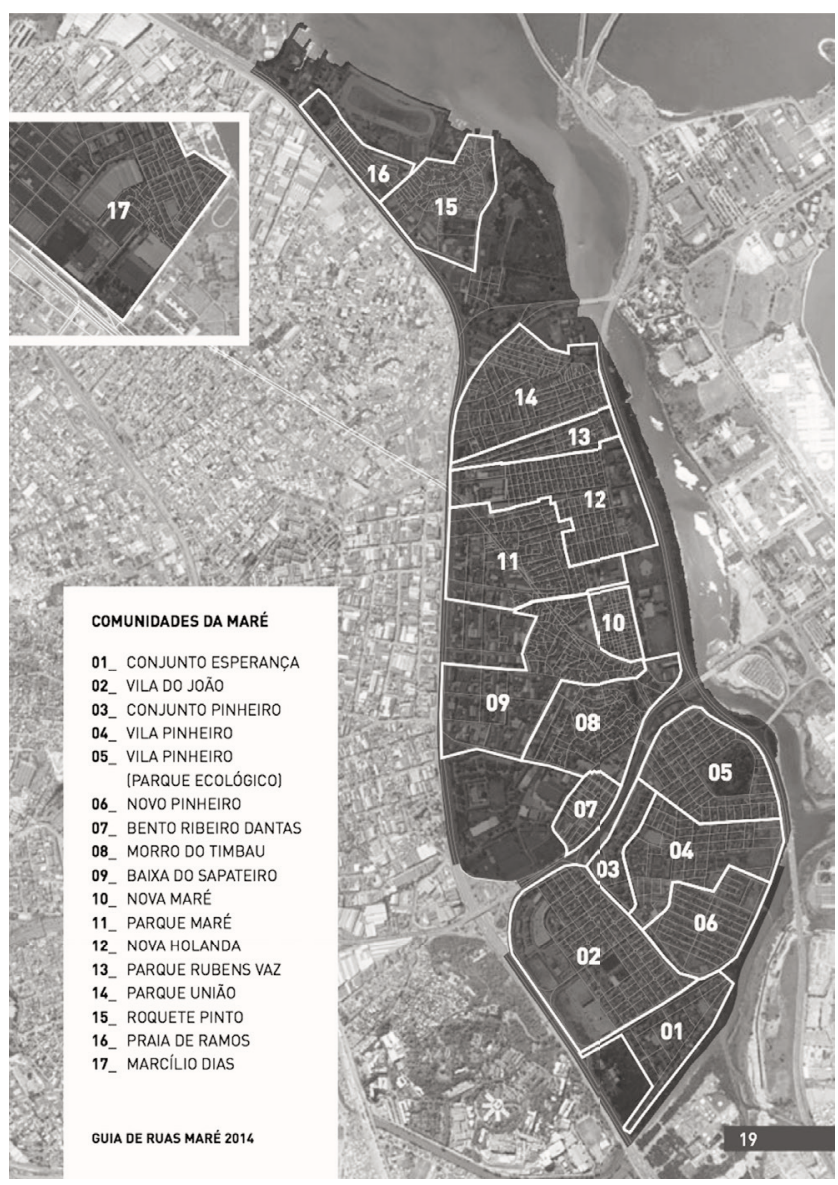

Figura 05 - Divisão das 16 comunidades do conjunto de favelas da Maré. Fonte: Guia de Ruas da Maré, 2014 


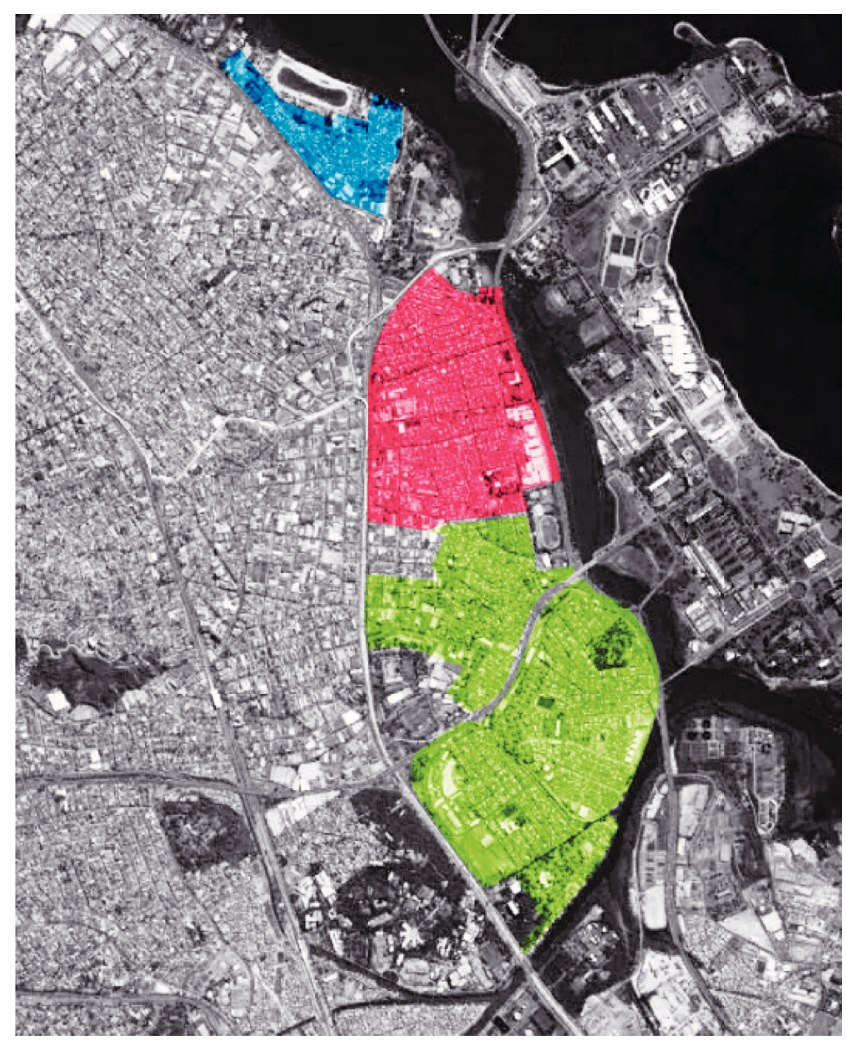

Figura 06 - Divisão de grupos armados no território da Maré. Em azul, a milícia - ou grupos paramilitares-; em vermelho, 0 Comando Vermelho; em verde, o Terceiro Comando Puro. Fonte: Bruna Montuori, 2019

Nesta trajetória, em 2007, a Redes da Maré foi formalizada como um grupo educacional que auxiliava jovens do território alcançarem um espaço na universidade. O grupo foi conduzido pela moradora e doutora Eliana Sousa Silva que focou sua trajetória acadêmica no engajamento político e na qualidade de educação para crianças e jovens na Maré. Ao longo dos últimos doze anos, a organização cresceu e se expandiu rapidamente e hoje está estruturada em quatro eixos de trabalho: Educação; Desenvolvimento territorial; Arte, cultura, identidade e memória; e Direito à segurança pública e acesso a justiça.

Neste âmbito, o projeto Maré Sem Fronteiras focou na luta contra a estigmatização existente entre as diferentes favelas do território. Em razão da forte influência de criminalidade, proveniente da rivalidade entre dois grupos armados locais, uma milícia e a entrada repressiva da polícia militar, o projeto foi criado com o intuito de reduzir as fronteiras de violência, especialmente entre crianças e jovens que cresceram com estas disputas. Por meio de bicicletadas e atividades voltadas para a mobilidade urbana, o projeto consistiu em atividades que levavam jovens de diferentes favelas para conhecer e se relacionar a outras.

Em meio a estas atividades, a inserção de arte e tecnologia permitiu um trabalho que envolvesse a construção de um triciclo multimídia, que percorreu a Maré com suas luzes de led e música alta, a fim de convidar moradores para discutir as fronteiras do território. O projeto, idealizado pelo grupo de pesquisa do território Datalabe (2019) envolveu diferentes trocas entre moradores e frequentadores da Maré, envolvendo ciclo ativistas, eletricista, jovens do projeto, entre outros.

Além disso, o triciclo ainda projetava vídeos que abordavam o assunto e abriam espaço para diálogos e discussões sobre o tema em praças e outras áreas livres. Em meio a este projeto, as bicicletadas também tiveram um papel forte de sustentabilidade no território. Com a participação do Muda Maré, coletivo de estudantes de biologia da UFRJ, os passeios ciclísticos carregavam mudas que eram plantadas em diferentes espaços públicos locais. Somado a isso, a parceria com grafiteiros trouxe a arte junto ao tema das fronteiras, transformando os mesmos espaços públicos com estêncis e pinturas, que não só requalificavam os espaços, mas promoviam aprendizados aos jovens e noções sobre cooperação. O projeto foi financiado primordialmente pela organização, porém contou com o apoio efetivo de uma campanha de financiamento coletivo em 2016.

Essas formações coletivas assumem um papel fundamental no questionamento das representações socioculturais das pessoas nos espaços de pertencimento da cidade. Elas se efetivam no sentido de mudar certas relações de alteridade à medida que se vinculam aos interesses comuns dos cidadãos. Tratam-se experiências de microescala, formas potentes de interação das pessoas para melhoria do ambiente urbano, reiteram a ideia da cidade como espaço aberto passível de transformações, de constante ressignificação e de participação proativa das pessoas. Práticas que revelam modos inovadores que envolvem diferentes parceiros, na construção de uma cidade melhor, no que tange as ações, as novas atitudes com relação a vida coletiva. São alternativas simples, criativas e que podem gerar mudanças significativas nas comunidades e nas cidades.

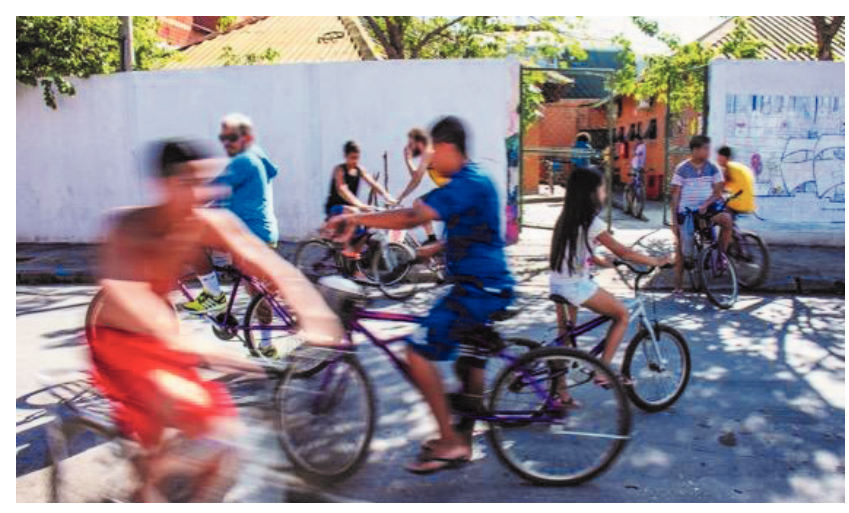

Figura 07 - Passeio ciclístico livre em frente Lona Herbert Vianna, Nova Maré, Rio de Janeiro. Fonte: Douglas Lopes, 2017. 


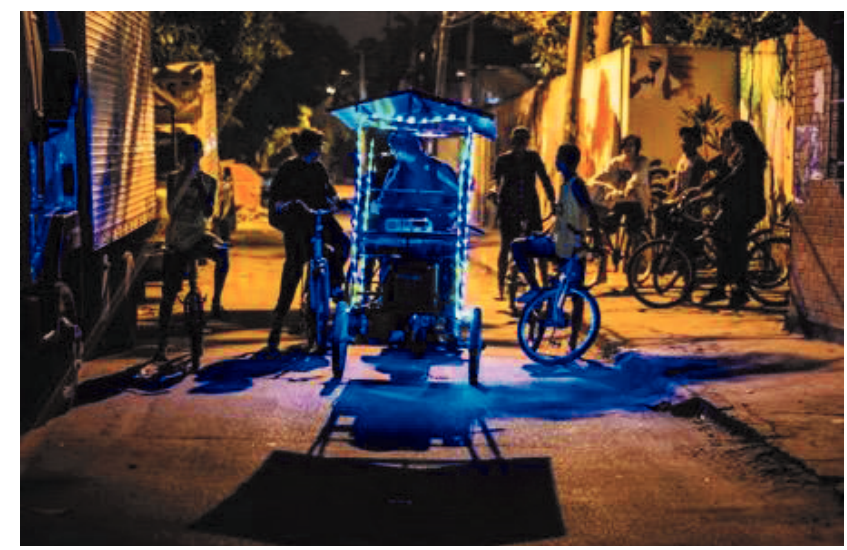

Figura 08 - Passeio ciclístico com triciclo multimídia cruzando a Maré Fonte: Douglas Lopes, 2016.

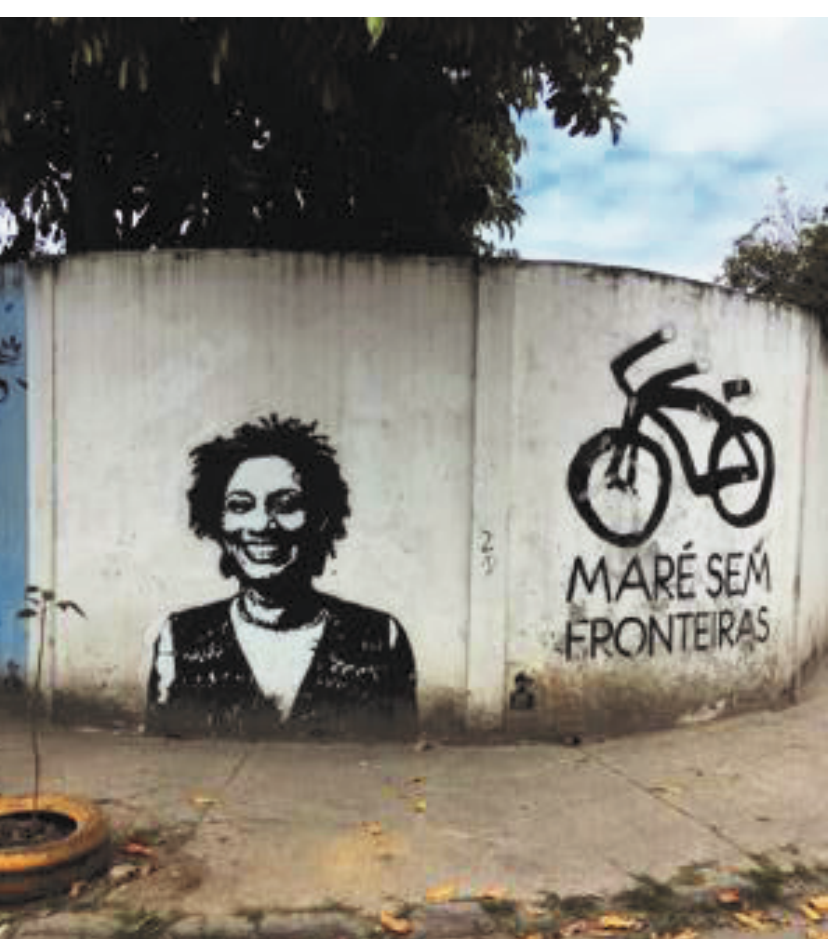

Figura 09 - Grafitti com logotipo Maré sem Fronteiras. Fonte: Bruna Montuori, 2019.

Não se trata aqui, da noção de "comunidade" associada a um sentido de longa duração, do confiável, amigável, de grupo de pessoas solícitas e receptivas, ou de um eufemismo no uso termo, explorado nas últimas décadas, para suavizar a noção pejorativa do termo "favela". Trata-se da experiência "em comunidades", associada a ideia de trocas, de encontros que nos propõe pensar a ideia do "ser-em-comum", para pensar trabalhar "em comunidade", como uma formação coletiva porosa e temporária, não necessariamente vinculada a noção de um lugar, cujas as forças de coesão são produzidas sob interesses e condições peculiares que afetam os modos de interação que nela ocorrem, conforme a reflexão de Vera Pallamin (2006).
A ideia de participação e envolvimento em ações de interesse comunitário não é recente nas favelas, aliás é inerente à história desses locais, cuja existência está vincula à luta e a mobilização constante da população por direitos básicos e pela lógica da coesão e de cooperação. Nos anos 1980 começam a aparecer nas favelas, de forma mais organizada, ações e movimentos populares de bases locais que procuravam sensibilizar a população para a participação no sistema político, pelo direito à terra, à moradia e à cidadania. Na década de 1990 esta perspectiva de participação e de mobilização, passa a ser reiterada pelas políticas públicas nos governos de gestão popular que passam a implementar mecanismos governamentais de envolvimento da população no uso de recursos para construção de equipamentos públicos e de melhorias na infraestrutura urbana. Para Mário Brum, (2019) esses processos impulsionaram e incentivaram a mobilização dessas populações para reinvindicação e proposição de intervenções de interesses coletivos nos seus territórios.

Os espaços urbanos são por definição territórios de partilha coletiva, cuja apropriação não pode ser exercida por ninguém em particular, mas por grupos com a incorporação das iniciativas de interesses locais, reconhecendo o potencial participativo existente nestes territórios. No entanto ainda são poucas as experiências em que designers estão envolvidos nestes processos.

\section{ALGUNS PARADIGMAS COLOCADOS PARA O DESIGN NESTE CONTEXTO}

As experiências de cocriação em espaços públicos podem levantar questões significativas para a transformação e a melhoria dos modos de vida e usos dos espaços das cidades, sobretudo para essas populações. Podem não apenas apontar aspectos significativos de convivência e de cuidado dos cidadãos com as cidades, mas podem gerar dados relevantes para um urbanismo mais condizente com as realidades locais.

De acordo com Sanders e Stappers (2008), cocriação é um termo muito amplo, com aplicações variando do físico ao metafísico e do material ao espiritual. No contexto do design, os autores trazem cocriação para se referirem a qualquer ato de criatividade coletiva, ou seja, a criatividade que é compartilhada pelas pessoas.

As cocriações apresentadas aqui trazem à tona a possibilidade de um modo coletivo e articulado de produção ativa nos espaços públicos, reiterando a noção destes, como lugares de construção de relações afetivas e de cidadania. Não envolvem a participação de designers especializados, mas podem revelar aspectos importantes para este campo. 
Sugerem a existência de modos e organizações espontâneos na cidade e podem ser associadas ao sentido das comunidades criativas, conforme defendido por Ézio Manzini; “... pessoas que de alguma forma colaborativa, inventam, aprimoram e gerenciam soluções inovadoras para novos modos de vida. Nascem a partir de problemas colocados pela vida cotidiana contemporânea". (MANZINI, 2008, p.65)

É possível que o design projete para e com as comunidades criativas, analisando suas tipologias especíicas, observando suas forças e fraquezas, intervindo para tornar os seus contextos mais favoráveis. Segundo Cameron Tonkinwise (2016), o papel dos especialistas em design é alimentar e apoiar os projetos individuais e coletivos e, portanto, as mudanças que estes podem originar. No entanto, o reconhecimento do lugar de fala do campo é essencial para que haja uma relação mais participativa, horizontal e política, em que todos os atores envolvidos estão conscientes de suas ações e decisões. Uma vez que os espaços citados carregam um longo histórico de marginalização considerando as maneiras como se constituíram nos contextos urbanos, a relação designer-cidadão não deve ser observada a partir de uma perspectiva singular, mas sim dialética, em que a ação de um afeta diretamente na do outro e, por consequência, na qualidade do espaço.

Cabe ao design elaborar sua proposição a partir das capacidades e potências presentes nos coletivos e nos territórios das cidades, de forma distinta aos seus métodos, processos e ferramentas tradicionais. Trata-se de valorizar as iniciativas bottom up (de baixo para cima) que possam revelar formas de organização espacial ou de valores das cidades. Além disso, adotar na sua concepção e na sua prática dispositivos e ferramentas participativas e criativas que envolvam e façam integrar cidadãos, designers, planejadores urbanos, como agentes públicos na mudança da qualidade dos lugares. Mas, para isso é preciso aproximar das experiências cotidianas, investigar os aspectos da vida social das pessoas, os modos como se interagem e atuam coletivamente. E acumular o máximo de conhecimento sobre como potenciar e agir criativamente. Portanto, é necessário expandir as abordagens já existentes, como as experiências de codesign, que correspondem a uma forma específica de criatividade coletiva;

... o codesign é um exemplo específico de cocriação. Se refere, para algumas pessoas à criatividade coletiva de designers e colaboradores. (...) é um sentido mais amplo para se referir à criatividade de designers e pessoas não treinadas em design, trabalhando juntos no processo de desenvolvimento de design. (SANDERS E STAPPERS, 2008, p. 9)
Sugere-se a adequação desses processos de modo a ampliar a atuação do design nos espaços públicos. Os recursos de design podem adquirir qualidades simbólicas, ao estabelecer modificações concretas, construindo cenários que podem contribuir para a definição de traços da identidade local, de características referentes ao comportamento, à paisagem urbana, à história e à memória de cada lugar, considerando a participação dos cidadãos.

Conforme Giulio Argan, "o valor de uma cidade é o que Ihe é atribuído por toda a comunidade. " (ARGAN, 1998, p.226). Neste sentido, é preciso entender a participação pública enquanto dimensão natural e essencial dos projetos para/nos espaços públicos e questionar e romper com os sistemas já estabelecidos. Se encararmos a urbanidade como um processo participativo, que envolve muitos atores com diferentes perspectivas a vários níveis, poderá existir um grande potencial para a integração com o design, no sentido de propor ferramentas participativas. Se pensarmos nas cidades contemporâneas e na complexidade das questões que afligem o uso e as relações das pessoas com seus espaços, podemos pensar no design como um modo não só de contribuir na resolução dos problemas ou como um modo de redefinir os contextos cotidianos da vida das pessoas. Ainda que de forma tímida, observa-se uma emergência dos cidadãos, de tomar conta, diretamente das suas localidades, de construir soluções que as políticas públicas não dão ou demoram a realizar, eles estão a reagir pró-ativamente como resposta às necessidades efetivas da população.

São inúmeros os desafios colocados ao design contemporâneo, que extrapolam sua abordagem global que se manifesta na criação de novos produtos, numa perspectiva comunicativa e ambiental, quando integrado a toda a ordem que envolve a esfera pública. $O$ foco do design neste estudo recai sobre o seu papel, para além das suas noções tradicionais de funcionalidade, racionalismo e de seu caráter industrial. Remete à sua relação dimensional com a vida social, como um modo de experimentação criativo e de transformação. Aproximar designers de iniciativas comunitárias permite o reconhecimento das ações realizadas por organizações e coletivos, não apenas gerando visibilidade à suas atuações, mas na promoção de um intercâmbio de aprendizados. Tal aproximação abre espaço para que cada vez mais designers atuem de forma integradora, reconhecendo o saber fazer vernacular de transformação do espaço urbano que já existe. Desta forma, advogamos por uma prática de design que vise alcançar a emancipação dos usuários/fazedores nos processos projetuais, em oposição à ideia que a coloca apenas como 
uma medida para resolução de problemas. Assim, não se trata somente da emancipação dos usuários, mas do próprio profissional, visto que seu papel "pode parar na descoberta e na articulação da questão - [em que] identificar e expressar o problema não perpetua necessariamente o papel do design (...) ", como sugere o pesquisador (DI SALVO, 2009, p. 60 - tradução das autoras).

No momento em que designers se libertam da responsabilidade de serem apenas solucionadores de problemas em projetos colaborativos e se permitem a uma atitude ativista, o cerne do trabalho passa a ser o processo, que passa a ser mais rico em termos de aprendizados, experiências e reflexões. Ferrara (2002) coloca que o designer é o criador da percepção dos novos processos relacionais entre as várias linguagens que estão presentes no cotidiano, e sem seu resgate reflexivo, o desenho "se submete à tecnologia dos materiais e dos procedimentos que lhe são inerentes e prescritivos ou à esterilidade da competência técnica (...) ", passando "a ser seu único parâmetro, seu único valor". (FERRARA, 2002, p.52). Sanders e Stappers (2008) tocam neste ponto ao fazer uma retrospectiva acerca da abordagem de design centrado no usuário, iniciada nos anos 1970 e pulverizada nos anos 1990, considerada a mais útil no desenvolvimento de produtos para consumidores. Contudo, os autores reconhecem que atualmente a abordagem não contempla a escala de complexidade dos desafios que enfrentamos hoje:

Já não estamos simplesmente projetando produtos para usuários. Estamos projetando para as experiências futuras de pessoas, comunidades e culturas que agora estão conectadas e informadas de maneiras inimagináveis (...). Estamos passando do design de categorias de 'produtos' para projetar o propósito das pessoas. (SANDERS E STAPPERS, 2008, p.10).

Ao projetar o propósito das pessoas, profissionais correm o risco de tomar para si toda a responsabilidade do processo, algo comumente visto e ainda recente nas reflexões revisadas em estudos de design. Em razão disso, é fundamental refletir sobre uma postura responsiva no design, que ao invés de atribuir toda a responsabilidade nas mãos do profissional, coloca-o como mediador, integrado ao projeto, como ator participante. Esta concepção, sugerida pelos pesquisadores Adam Thorpe e Lorraine Gamman (2011), evidencia que as decisões tomadas são uma resposta ao contexto, a partir da colaboração de vários atores, assim sustentando múltiplos agenciamentos.

Finalmente, ao passo que o design carrega uma abordagem fraternalista em oposição à paternalista, reconhecendo que o profissional contribuirá de acordo com o contexto e as suas habilidades, pode assumir um agenciamento e responsabilidades similares ao de outros atores no processo. Partindo de tais pressupostos, a prática coletiva de fazer design desloca seu viés de ação para suportar quem já faz e transforma a cidade, abrindo outros caminhos para o campo, permitindo outras perspectivas mais plurais e embasadas no que acontece cotidianamente na cidade.

\section{AGRADECIMENTOS}

Aos coordenadores e participantes dos projetos Favela Bela e Maré Sem Fronteiras- Redes da Maré. Ao CNPq pelo financiamento da pesquisa de doutorado de Bruna Ferreira Montuori (processo n. 201660/2018-0). Agradecimentos à FAU-USP e a Royal College of Art.

\section{REFERÊNCIAS}

ALCOFF, L. 2008. The Problem of Speaking for Others. Just Methods: an interdisciplinary feminist reader. Boulder, CO: Paradigm Publishers, 2008, p. 487-492.

An epistemology for the next revolution. In Trans modernity: Journal of Peripheral Cultural Production of the Luso-Hispanic World, v.1, n.2, 2017, p. 67-78.

ARGAN, Giulio C. História da arte como história da cidade. São Paulo: Martins Fontes, 1998.

ARANTES, O.; VAINER, C.; MARICATO, E. A Cidade do pensamento único: Desmanchando consensos. Petrópolis: Editora Vozes, 2002.

BERTELLI, G.B. (Org.). Vozes à margem: periferias, estética e política. São Carlos: Editora EFISCAR, 2017. BONSIEPE, Gui. Design, cultura e sociedade. São Paulo: Blucher, 2011.

BRUM, Mário. Breve História das Favelas Cariocas - das origens aos Grandes Eventos. In: Maia, R. O Rio (Re)visto de suas margens. Rio de Janeiro: Letra Capital, 2019, p. 108-135.

CANCLINI, N. G. Las cultura populares en el capitalismo. Mexico, DF: Nueva Imagen, 1989.

CARDOSO, F. de A. O Universo simbólico do design gráfico vernacular. 2010, 193 f. Tese (Doutorado em Design) - Pontifícia Universidade Católica do Rio de Janeiro, Rio de Janeiro, 2010.

DE CERTAU, M. A Invenção do Cotidiano: artes de fazer. São Paulo: Vozes, 2014.

DI SALVO, Carl. Design and the Construction of Publics. In: Design Issues, v.25, no 1, Winter 2009, p. 48-63, Cambridge: MIT Press, 2009.

ESCOBAR, Arturo. Autonomía y Diseño. La realización 
de lo comunal. Cauca: Universidad del Cauca, 2016.

Encountering development: the making and unmaking of the third world. New Jersey, NJ: Princeton University Press, 1995.

FERRARA, Lucrécia. D. Design em espaços. São Paulo: Rosari, 2002.

FEZER, J. Design for a post Neo-liberal City. E-flux Journal, 17, jun 2010. Disponível em: <http://www.e-flux.com/journal/design-for-a-post-neoliberal-city/>. Acesso em: 29 Jan. 2017.

FIGUEIREDO, Poli; Gabriel MAZZOLA. 0 discurso e a prática da smart city: perspectivas críticas e aproximações sistemáticas no contexto de metrópoles latino-americanas. 2018. Dissertação (Mestrado em Tecnologia da Arquitetura) - Faculdade de Arquitetura e Urbanismo, Universidade de São Paulo, São Paulo, 2018.

FUNDAÇÃO JOÃO PINHEIRO. Resultados do déficit habitacional

http://www.fjp.mg.gov.br/index.php/noticias-em- destaque/4154-fundacao-joao-pinheiro-divulga-resultados-do-deficit-habitacional-no-brasil. Acessado em: 13/07.2019.

GAMMAN, Lorraine; THORPE, Adam. Design with society: why socially responsive design is good enough. In Co-Design, v. 7, no 3-4, 2011, p. 152-165.

HCD. HUMAN CENTERED DESIGN. Kit de Ferramentas. $\mathbf{1}^{\mathbf{a}}$ e 2a Edições. Fundação Bill \& Melinda Gates Trad. Tennyson Pinheiro, José Colucci e Isabela de Melo.

IBGE - INSTITUTO BRASILEIRO DE GEOGRAFIA E ESTATÍSTICA. Síntese Cidades.

https://cidades.ibge.gov.br/brasil/mg/belo-horizonte/ panorama. Acessado em: 13/07/2019.

ICSID. INTERNATIONAL COUNCIL OF SOCIETIES OF INDUSTRIAL DESIGN. Definition of Design. Disponível em: https://web.archive.org/web/20090903040817/ http://www.icsid.org/about/about/articles31.htm. Acessado em: 03/05/2019.

IDEO. Design Kit: The Human-Centered Design Toolkit. Disponível em: https://www.ideo.com/post/ design-kit. Acessado em: 07/09/2019.

JACQUES, B,P. Estética da ginga: a arquitetura das favelas através da obra de Hélio Oiticica. Rio de Janeiro: Casa da Palavra/RIOARTE,2001.

Microresistências urbanas: por um urbanismo incorporado. in ROSA, Marcos. Microplanejamento: Práticas urbanas criativas. Editora Cultura: São Paulo, 2011.

Montagem de uma outra herança.
Vídeo para obtenção do título de Professora Titular na Faculdade de Arquitetura e Urbanismo da UFBA. Disponível em: https://www.youtube.com/watch?v=V5puc67kZuw. Acessado em: 5 Mar. 2019.

JULIER, G. From Design Culture to Design Activism. In Design and Culture, v.5, n², p. 212-236, july 2013, London: Bloomsbury, 2013.

LEFEBVRE, Henri. A sociedade urbana. A revolução urbana. Trad. Sérgio Martins, Margarida M. Andrade. Belo Horizonte: Ed. UFMG, 1999.

A produção do espaço. Trad. Doralice

B. Pereira e Sérgio Martins (do original: La production de l'espace) 4. Éd. Paris: Éditions Anthropos, 2000 [1974]).

LEITE, J. de S. (org.). Encontros: Aloisio Magalhães. Rio de Janeiro: Beco do Azougue, 2014.

LENSKJOLD, T. U.; OLANDER, S.; HALSE, J. Minor Design Activism: Prompting Change from Within. In: Design Issues, v.31, no 4, Autumn 2015, p. 67-78, Cambridge: MIT Press, 2015.

MAGALHÃES, A. O que o design industrial pode fazer pelo país? In: Revista Arcos, Rio de Janeiro. V.1, 1998, p 8-12.

MANZINI, Ézio. Design para inovação social e sustentabilidade: comunidades criativas, organizações colaborativas e novas redes projetuais. Rio de Janeiro: E-Papers, 2008.

Quando todos fazem design para

inovação social. Trad.Luiza Araújo. Editora Unisinos: São Leopoldo - RS, 2017.

MARICATO, Ermínia. Metrópole na periferia do capitalismo: ilegalidade, desigualdade e violência. São Paulo: Hucitec, 1996.

MEHROTRA, Rahul. Working in Bombay: The City as Generator of Practice. In Anytime, June, 1998, p. 6469. Disponível em: <http://www.rmaarchitects.com/ essays/working-in-bombay.pdf> Acesso em 13 Nov. 2017.

MONTUORI, B. F. Design, Favela e Ativismos: experiências e aprendizados com a Redes da Maré no Rio de Janeiro. 2018, 238f. Dissertação (Mestrado em Arquitetura). Faculdade de Arquitetura e Urbanismo, Universidade de São Paulo, São Paulo, 2018.

Origens e concepção de um curso de design para contextos reais na PUC-Rio: a primeira identidade. In BRAGA, M. da C.; FERREIRA, E. C. K. (Orgs.) Histórias do Design no Brasil III. Sao Paulo: Annablume, 2017, p. 79-99.

MONTUORI, B.F.M, ROSA, M., SANTOS, M. C. L. Design 
by means of citizen activism: three cases illustrated by the action of Coletivo Maré, Rio de Janeiro, Brazil. In The Design Journal, 20:sup1, S2973-S2990.

ONU-ORGANIZAÇÃO DAS NAÇÕES UNIDAS. Atlas do Desenvolvimento Humano (29 de julho de 2013). Disponível em: «Ranking decrescente do IDH-M dos municípios do Brasil» (PDF). Programa das Nações Unidas para o Desenvolvimento (PNUD). Acessado em 13/07/2019.

PALLAMIN, Vera. Intervenções urbanas e Comunidades: entre o o consenso e o dissenso. Revista do Instituto Arte das Américas. Belo Horizonte: Editora C/Arte, 2006

PAPANEK, Victor. Design for the Real World. Human Ecology Social Change. Londres: Paladin, 1974 PREFEITURA DE BELO HORIZONTE. Estatísticas e indicadores. Disponível em: https://prefeitura.pbh.gov. br/estatisticas-e-indicadores/indice-de-qualidade-de-vida-urbana Acessado em: 01/09/2019.

RANCIÈRE Jacques. $\mathbf{O}$ desentendimento. Trad. Ângela leite Lopes. Editora 34: São Paulo, 1995.

REDSTRÖM, J. Introduction: Defining Moments. In: Gunn, W., Donovan, J. (Eds). Design and Anthropology. Farnham: Ashgate, 2012, p. 83-100.
REDES DE DESENVOLVIMENTO DA MARE. Website da organização. Disponível em: https://redesdamare. org.br/. Acessado em 02/11/2018.

Censo Populacional da Maré. Rio de Janeiro: Redes da Maré, 2019.

RIBEIRO, D. O que é lugar de fala? Belo Horizonte, MG: Letramento, 2017.

ROSA, M. L. From modern infrastructures to operational networks. The qualification of local space at existing large scale utility infrastructure: a method for reading community-driven initiatives. The case of São Paulo. 2015, 350 f. Tese (Doutorado em Arquitetura) Universidade Técnica de Munique, Munique, 2015.

Microplanejamento práticas urbanas

criativas. São Paulo: Cultura, 2011.

SANDERS, E.N., STAPPERS, J.P. Co-creation and the new landscapes of design, Co-Design. Co-designInternational Journal of Co-creation In Design And The Arts. 4:1, 5-18, DOI: 10.1080/15710880701875068, 2008.

SOUSA SILVA, Eliana. Testemunhos da Maré. Rio de Janeiro: Mórula, 2015.

TONKINWISE, Cameron. Urgently Designing Cosmopolitan Localism in the Era of Xenophobia. In The Radical Designist, n.4, junho 2016, 2016, p. 2-19.

\section{AUTORES}

ORCID: https://orcid.org/0000-0001-7688-1105

BRUNA MONTUORI, M.Sc. | Royal College of Art | School of Architecture | Londres - Reino Unido | Correspondência para: Kensington Gore, South Kensington, London SW7 2EU, Reino Unido| E-mail: bruna.montuori@network.rca.ac.uk

ORCID: https://orcid.org/0000-0001-9216-4421

MARIA CECILIA LOSCHIAVO DOS SANTOS, Dra. | Universidade de São Paulo | Faculdade de Arquitetura e Urbanismo | São Paulo, SP - Brasil | Correspondência para: R. do Lago, 876 Butantã, São Paulo - SP, 05508-080 |E-mail: closch@usp.br

ORCID: https://orcid.org/0000-0002-0727-7294

MARIA LUIZA DIAS VIANA, M.Sc. | Universidade de São Paulo | Faculdade de Arquitetura e Urbanismo | São Paulo, SP Brasil | Correspondência para: R. do Lago, 876 - Butantã, São Paulo - SP, 05508-080 | E-mail: mluizaviana@usp.br

\section{COMO CITAR ESTE ARTIGO}

MONTUORI, Bruna; SANTOS, Maria Cecilia Loschiavo dos; VIANA, Maria Luiza Dias. Micro Resistências e Macro Potências em Espaços Urbanos: Perspectivas para o Design. MIX Sustentável, [S.I.], v. 5, n. 5, p. 67-80, dez. 2019. ISSN 24473073. Disponível em:<http://www.nexos.ufsc.br/index.php/mixsustentavel>. Acesso em: dia mês. ano. doi:https://doi. org/10.29183/2447-3073.MIX2019.v5.n5.67-80.

DATA DE ENVIO: $11 / 11 / 2019$

DATA DE ACEITE: $12 / 11 / 2019$ 